\title{
Üveitlere Romatolojik Yaklaşım
}

\author{
Rheumatologic Approach to Uveitis \\ Sertaç Ketenci ${ }^{1}$ iD, Ender Salbaş ${ }^{2}$ \\ 1 Romatoloji Kliniği, Çiğli Eğitim Araştırma Hastanesi İzmir/Türkiye
} 2 Fiziksel Tıp ve Rehabilitasyon Kliniği, Ömer Halisdemir Üniversitesi Tıp Fakültesi, Bor FTR Eğitim ve Araştırma Hastanesi, Bor, Niğde/Türkiye

\section{özeT}

Özet: Üveit terimi gözün kanlanmasını sağlayan katmanların inflamasyonunu ifade eder. Altta yatan neden idiyopatik olabileceği gibi, enfeksiyonların, romatolojik hastalıkların, ilaç yan etkilerinin bir yansıması olarak da karşımıza çıkabilir. Etiyolojisinde sistemik inflamatuvar patolojilerin yoğun olarak yer alması nedeniyle üveit tanılı hastaları oftalmologlar dışında en sık gören hekimler romatologlardır. Tanı, tedavi ve takip açısından en sık kullanılan sınıflandırma olan anatomik sınıflandırmada üveitler ön, orta, arka ve pan üveit olarak 4 ana grupta ele alınır. Ön üveitler, tüm üveitlerin \%80'ini oluşturur. Sebepleri olarak ön planda idiyopatik üveitler, spondiloartropatiler (SpA), herpetik virüsler ve Behçet hastalığı sayılabilir. Akut ön üveitli (AAU) hastalar kliniğe kızarık göz, fotofobi ve ağrı ile başvurur. Tipik olarak tek gözde inflamasyon görülür. Nadiren iki taraflı ataklar da saptanabilir. Kronik ön üveite Romatoloji pratiğinde AAU'ya göre daha nadir rastlanılmakla beraber, en sık ilişkili olduğu durum Jüvenil İdiyopatik Artrittir (JiA). Orta Üveite (IU) neden olan en sık iki etken Multipl Skleroz (MS) ve Sarkoidozdur. Diğer hastalıklar Sifiliz, Toksoplazma, Toksokara, Tüberküloz, EBV enfeksiyonları şeklinde sıralanabilir. Ön üveitlerde beklenen kırmızı göz, ağrı gibi semptom ve bulgular arka üveitlerde beklenmez. Ülkemizde arka üveit tanılı hastaların \%40'tan fazlasında Behçet Hastalığı bildirilmekteyken, Avrupa verilerinde idiyopatik üveitler, enfeksiyonlar ve Sarkoidoz gibi sebepler ön planda gözlenmektedir. Ülkemizde yapılan çalışmalarda panüveit sıklığı \%26,7 ile ön üveitten sonraki ikinci en sık üveit grubunu oluşturur. Behçet Hastalığı ve idiyopatik panüveit önde gelen iki sebebi oluşturmaktadır. Bu derleme ile üveitlerin romatoloji penceresinden kapsamlı olarak ele alınması amaçlanmıştır..

Anahtar Kelimeler: üveit, romatoloji, Behçet, spondiloartropati, inflamasyon

\section{ABSTRACT}

The term uveitis refers to inflammation of the layers that provide blood to the eye. The underlying cause may be idiopathic or reflection of infections, rheumatologic diseases and as a drug side effect. Due to the involvement of systemic inflammatory pathologies in the etiology; Rheumatologists are the most common physicians who see uveitis patients except ophthalmologists. According to anatomical structure, uveitis is classified into 4 main groups as anterior, middle, posterior and pan uveitis. This grouping; is the most commonly used classification in terms of diagnosis, treatment and follow - up. Anterior uveitis accounts for $80 \%$ of all uveitis. The causes of anterior uveitis include idiopathic uveitis, spondyloarthropathies (SpA), herpetic viruses and Behçet's disease. Patients with acute anterior uveitis (AAU) have complaints of red-eye, photophobia and pain. Inflammation is typically seen in one eye. Rarely, bilateral attacks can also be found. Chronic anterior uveitis is less common in rheumatology practice than AAU, but it's most common association is Juvenile Idiopathic Arthritis (IIA). The two most common causes of intermediate uveitis (IU) are Multiple Sclerosis (MS) and Sarcoidosis. Other diseases include Syphilis, Toxoplasma, Toxocara, Tuberculosis, EBV infections. Symptoms and signs such as red eye and eye pain that expected in anterior uveitis are not expected in posterior uveitis. Behçet's disease has been reported in more than 40\% of the patients with posterior uveitis in Turkey, while European data shows that idiopathic uveitis, infections and sarcoidosis are the main causes for posterior uveitis. In Turkey, the prevalence of panuveitis is $26.7 \%$ and it is the second most common uveitis group after anterior uveitis. Behçet's disease and idiopathic panuveitis are two leading causes. The aim of this review is to investigate the uveitis from rheumatology window comprehensively. .

Keywords: uveitis, rheumatology, Behçet's, spondyloarthropathy ,inflammation

\section{Giriş}

Uvea kelimesinin kökeni Latincedir ve üzüm anlamına gelir. Tıp terminolojisinde ise gözün kanlanmasını sağlayan iris, siliyer cisim ve koroid dokularını içeren göz katmanına verilen isimdir (1). Üveit terimi ile bu bölgenin ve bazen eşlik eden komşu bölgelerin inflamasyonuyla karakterize, onlarca etiyolojiye sahip hastalık grubu tanımlanmaktadır. ABD'de kalıcı körlügün \%10 kadarından üveit sorumlu tutulmaktadır (2). Diyabetten kat be kat az görülmesine rağmen diyabetik retinopatiye bağı körlük oranıyla üveite

Yazışma Adresi/Address for Correspondence: Sertaç Ketenci, MD, Romatoloji Kliniği, Çiğli Eğitim Araştırma Hastanesi, İzmir/Türkiye

E-Posta/E-Mail: drsertacketenci@hotmail.com || Tel: +905078665533

Received/Geliş Tarihi: 7 Kas 2019 || Accepted/Kabul Tarihi: 19 Kas 2019

Bu Eser Creative Commons Atıf-Gayriticari 4.0 Uluslararası Lisansı İle Lisanslanmıştır. This work is licensed under a Creative Commons

Attribution-NonCommercial 4.0 International License (CC BY-NC 4.0). 
bağlı körlük oranı hemen hemen eşittir. Bu durum da üveitlerin ne kadar yıkıcı seyredebildiğini göstermektedir.

Üveitler idiyopatik olabileceği gibi, enfeksiyonların, romatolojik hastalıkların, ilaç yan etkilerinin ve veya malignitelerin bir yansıması olarak karşımıza çıkabilir (3). Geçmişteki çalışmalarda \%60'lara varan oranlarda en sık grubu idiyopatik üveitin oluşturduğu bildirilmektedir. Ancak günümüzde gelişmiş tanı yöntemlerinin kullanılması ve uzun süreli izlemle bu oran \%38'lere kadar düşmüştür (4). Üveite sebep olabilen durumlar coğrafik ve etnik farklııklar da gösterebilmektedir. Örneğin çoğu batı ülkesinde halen en sık olarak idiyopatik üveitler görülmektedir. Ülkemizde yapılan bir çalışmada ise 3 . basamak göz hastalıkları kliniğine başvuran hastaların en sık üveit sebebi \%35 oranla Behçet hastalığı bulunmuştur (5).

Üveitlerin etiyolojisinde sistemik inflamatuvar patolojilerin yoğun olarak yer alması nedeniyle üveit tanılı hastaları oftalmologlar dışında en sık gören hekimler romatologlardır. Romatoloji ile diğer branşlar arasında gerçekleşen görüş alışverişinin önemli bir kısmını üveit vakalarının ayırııı tanısı, sistemik inflamatuvar bir hastalığa eşlik edip etmediği, romatolojik hastalığa bağlı üveitlerin takibi ve tedavisi oluşturmaktadır. Bu sebeple, bu derleme üveiti güncel bilgiler eşliğinde romatoloji perspektifi ile ele almayı amaçlamaktadır.

\section{ÜVEITLERIN SINIFLANDIRILMASI}

Üveitlerin sınıflandırılması ile hastayı takip eden hekimler arasında ortak bir dil oluşturularak tanı, takip ve tedavi basamaklarında süreci kolaylaştırmak amaçlanmaktadır. Bunu bir örnekle açıklamak gerekirse; ön kamarada sınırlı inflamasyonun kalıcı hasar riski nispeten azdır. Tedavisinde konservatif yaklaşımlar ve lokal tedaviler tercih edilebilir. Ancak arka kamarada, optik siniri etkileyen bir inflamasyona hızlı ve agresif tedavi gerekecektir. Yine ön ve arka üveit etiyolojisinde farklı hastalıklar olduğu bilinerek spesifik tetkiklerle tanıya gidilebilecektir.

Üveitlerin en öncelikli sınıflandırması etiyolojik sınıflandırmadır. Etiyolojik olarak idiyopatik, enfeksiyöz ve non enfeksiyöz olarak üç ana grup bulunmaktadır. Nedeninde enfeksiyonun yer almadığı üveitler romatolojinin ilgi alanına girmektedir. Eskiden prognoz ve tedavi yönüyle klinisyenler için önemli iken günümüzde popülerliğini yitirmiş bir sınıflandırma yöntemi ise granülomatöz ve non-granülomatöz üveit ayırımıdır (6). Üveitlerin yaklaşık \%70-80'lik bir kısmını non-granülomatöz üveitler oluşturur. Romatoloji pratiğinde daha sık rastladığımız insan lökosit antijeni (HLA) - B27 veya Behçet ilişkili üveitler bu grupta yer almaktadır (7). Nongranülomatöz üveitler daha çok ön segmenti tutar ve ağrı, fotofobi kızarıklık belirtileri gösterme eğilimindedir. Kornea endotelinde presipitatlar, ön kamarada hücreler ve eksuda gözlenebilmektedir. Granülomatöz üveit ise sinsi başlangıçlı, ağrı ve foto fobinin daha geri planda olduğu, iri yoğun presipitatlar ve Koeppe-Busacca nodüllerinin gözlenebildiği kötü prognozlu bir üveit şeklidir. Tüberküloz, Sifiliz, Lepra, Bruselloz, Kedi Tırmı̆̆ Hastalığı, Lyme hastalığı, sempatik oftalmi ve kontakt lens kullanımına bağlı üveit bu duruma sebep olabilir. İnflamatuvar hastalıklardan Sarkoidoz, Granülomatöz Polianjit, Crohn Hastalığı ve Blau Hastalığı göz önünde bulundurulmalıdır. Granülomatöz üveitin varlığı altta mutlaka sistemik granülomatöz bir hastalığın yattı̆̆ının kanıtı değildir. Aynı şekilde granülomatöz sistemik hastalıkların seyrinde görülen üveitler her zaman granülomatöz yapıda olmaz ve nongranülomatöz üveit olarak da karşımıza çıkabilmektedir. (8)

Tanı, tedavi ve takip açısından en sık kullanılan sınıflandırma anatomik sınıflandırmadır. The Standardization of Uveitis Nomenclature (SUN) çalışma grubunun sınıflandırmasına göre üveitler ön (anterior), orta (intermediate), arka (posterior) ve pan üveit olarak dört ana grupta incelenir (9) (Tablo 1).

Tablo 1. SUN çalışma grubu üveitlerin anatomik sınıflandırılması

\begin{tabular}{|cll|}
\hline Üveitin tipi & \multicolumn{1}{c|}{$\begin{array}{c}\text { Primer } \\
\text { inflamasyon } \\
\text { bölgesi }\end{array}$} & Etkilenen bölgeler \\
Ön üveit & $\begin{array}{l}\text { Ön odada } \\
\text { inflamasyon (iris, } \\
\text { Ön siliyer cisim) }\end{array}$ & $\begin{array}{l}\text { İrit } \\
\text { İridosiklit } \\
\text { Ön siklit }\end{array}$ \\
& & Pars planitis, \\
Orta üveit & Vitrea & $\begin{array}{l}\text { Arka siklit, } \\
\text { Hiyalit }\end{array}$ \\
& & Fokal, multifokal \\
& & veya diffüz koroidit \\
& & Koryoretinit \\
& & Retinokoroidit \\
Arka üveit & Retina veya koroid & Retinit \\
& & Nöroretinit \\
& & Retinal vaskülit \\
& & \\
& Ön kamara, vitrea & \\
& ve retina veya & \\
& koroid & \\
& &
\end{tabular}




\section{Ön Üveitler:}

Ön kamarada inflamasyonla seyreden üveitler ön üveit olarak adlandırıır. Ön üveitler gelişmiş ülkelerde oftalmologların en sık gördügü üveit tipidir. Tüm üveitlerin \%80'ini oluşturur. Tutulum yerine göre irit veya iridosiklit şeklinde de romatologlara konsülte edilebilmektedir. Çoğunluğunda altta yatan bir sebep bulunamaz ve idiyopatik üveitler bu grubun önemli bir kısmını oluştururlar (1). Ülkemizde de \%42-52 oranla en sık görülen üveit tipi ön üveittir (5-10).

Batılı ülkelerde ön üveit sebepleri olarak ön planda idiyopatik üveitler, spondiloartropatiler (SpA), herpetik virüsler görülmektedir ve Behçet hastalığı neredeyse ön üveit sebepleri arasında anılmamaktadır (11). Oysa ülkemizde Behçet Hastalığı kimi çalışmalarda idiyopatik sebeplerden sonraki ikinci en sık ön üveit nedeni olarak anılmakta, tüm ön üveitlerin yaklaşık \%9-30'luk bir kısmını oluşturmaktadır (5-10). Yine panüveit yapan diğer hastalıkların da ön üveit şeklinde başlayıp panüveite dönebileceği akılda tutulmalıdır.

Ön üveitler klinik seyrine göre akut ve kronik olarak sınıflandırılabilir.

Akut ön üveitle (AAU) gelen hastaların yarısında altta yatan bir sebep bulunamaz. Bunlar idiyopatik AAU'yu oluştururlar. AAU'lu hastaların yaklaşık yarısında HLA B-27 geni pozitif olarak bulunur. HLA-B27 pozitif ön üveitli vakaların da yarısında altta yatan bir SpA tespit edilebilir (12).

Akut ön üveitli hastalar kliniğe kızarık göz, fotofobi ve ağrı ile başvurur. Tipik olarak tek gözde inflamasyon görülür. Nadiren iki taraflı ataklar da saptanabilir. Ön kamara muayenesinde inflamatuvar hücreler saptanabilir ve bunlar arka korneal endotelyumda depolanıp keratik presipitatları oluşturabilir. Ön üveite bağlı inflamasyon sınırlı kalsa da ön ve arka sineşilere sebep olarak durumu karmaşık hale getirebilir. Yaygın ön sineşi, aköz sıvının drenajını bloke ederek sekonder glokom, katarakt ve görme kaybına sebep olabilir (13). Ataklar sırasında ciddi göz hasarı beklenmemesi, ön üveitlerin bazen yetersiz tedavi edilmesine ve uzun dönemde ciddi komplikasyonlara yol açabilmektedir.

Ciddi bir ön kamara inflamasyonu, yoğun lökosit ve tortu oluşturmaya yetecek kadar fibrin varlığında hipopiyon görünümüne neden olur . Hipopiyon yapabilecek sebepler; enfektif tutulumlar, Behçet Hastalığı, HLA-B27 ilişkili üveit, SpA ve bazı kaynaklarda Sarkoidoz olarak gösterilmiştir (14). Enfektif hipopiyon ve HLA-B27 ilişkili hipopiyonda bol fibrinli bir eksuda ve yoğun görünümde hipopiyon vardır. Buna karşılık, Behçet Hastalığındaki hipopiyon az fibrinli ve hastanın göz hareketiyle yer değiştirebilen tarzdadır (15). Behçet'e bağlı hipopiyonda, HLA-B27 ilişkili hipopiyondan farklı olarak, inflamasyon çoğu zaman arka üveayı da etkiler. Daha önceleri ülkemiz için hipopiyonlu üveit denilince ilk akla gelen neden \%80'lere varan oranla Behçet hastalığı iken tanı ve tedavi yöntemlerindeki gelişmeler sayesinde Behçet hastalığında hipopiyonlu üveit \%9'a kadar gerilemiştir (13). Hipopiyonun diğer nadir görülen nedeni, AIDS hastalarında Rifabutin profilaksisinde görülebilen ilaca bağı hipopiyonlu üveittir (Tablo 2). Aslında hipopiyon olmamakla beraber tümör hücrelerinin ön kamarada birikimi veya kullanılan triamsinolonun katman oluşturması gibi durumlar da hastada psödo hipopiyon görünümü verebilir (16).

Kronik ön üveit nedenleri; idiyopatik, Fuchs heterokromik iridosikliti, Herpes virüsler, diğer kronik enfeksiyonlar ve tümör vb. taklit edici durumlara bağlı olanlar şeklinde sıralanabilir (17). Romatoloji pratiğinde AAU'ya göre daha nadir görülmekle beraber, en sık ilişkili olduğu durum Jüvenil i̇diyopatik Artrittir (JiA). JiA'lı çocukların \%12-17'sinde üveit görülür. Entezit ilişkili artriti olanlarda veya HLA-B27 ilişkili grupta AAU şeklinde görülse de özellikle ANA(+) oligoartiküler JiA grubunda \%30'lara varan kronik ön üveit bildirilmiştir. JiA'da görülen kronik ön üveit, AAU'ya göre daha sinsidir. Asemptomatik olabilmesi sebebiyle komplikasyona meyillidir ve ciddi görme kayıpları yaşanabilmektedir (13).

Behçet ve Sarkoidoz gibi durumlar kronik ön üveite neden olabilen diğer durumlardır. SpA, AAU ile özdeşleşmiş olsa da inflamatuvar barsak hastalığı ilişkili enteropatik artritler ve psöriyatik artrit (PsA) hastalarındaki tutulum bilateral kronik ön üveit olarak karşımıza çıkabilmektedir.

\section{Orta Üveitler:}

Orta (Intermediate) üveit (IU) inflamasyonun vitröz ve periferik retinaya sınırlı olduğu durumda verilen isimdir. Pars planitis, arka siklit, hiyalit de orta segment inflamasyonun yerini gösteren alt terimlerdir. Orta üveitler büyük oranda her iki gözde tutulumla seyreder ve önemli 
kısmını idiyopatik üveitler oluşturmaktadır (18). Pars planitis olguların yaklaşık yarısından sorumludur ve enfeksiyöz veya sistemik bir etiyoloji olmaksızın şiddetli inflamasyonla seyreden bir orta üveittir (19). IU'ya neden olan en sık iki inflamatuvar etken Multipl Skleroz (MS) ve Sarkoidozdur ( 20).
Sifiliz, Toksoplazma, Toksokara, Tüberküloz, EBV, kedi tırmığı hastalığı, Tübülointerstisyel Nefrit ve Üveit Sendromu, intraoküler lenfoma, HIV, Fuchs Heterokromik İridosikliti diğer orta üveit sebepleri olarak sayılabilir.

Tablo 2. Ilaçların neden olduğu Üveitler

\begin{tabular}{|c|c|}
\hline Sistemik İlaçlar & Üveit Tipi ve Şiddeti \\
\hline $\begin{array}{r}\text { Bifosfonatlar (alendronat, ibandronat, risedronat, zoledronat, } \\
\text { pamidronat), }\end{array}$ & Ön üveit (hafiften şiddetliye kadar) \\
\hline Sidofovir & Ön üveit (hafiften şiddetliye kadar) \\
\hline Dietilkarbamazepin & Ön-orta-arka üveit (hafiften şiddetliye kadar) \\
\hline $\begin{array}{r}\text { Florokinolonlar (siprofloksasin, levofloksasin, moksifloksasin, } \\
\text { norfloksasin, gatifloksasin) }\end{array}$ & $\begin{array}{l}\text { Ön üveit (hafiften şiddetliye kadar); iris transillüminasyon } \\
\text { defekti ile ilişkili olabilir }\end{array}$ \\
\hline Ibuprofen & Ön üveit (hafif) \\
\hline Oral kontraseptifler & Ön üveit / retinal vaskülit \\
\hline Kuinidin & Ön üveit (hafif veya orta) \\
\hline Rifabutin & Ön üveit (orta veya şiddetli); hipopiyon, retinal vaskülit \\
\hline Sulfonamidler & Ön üveit (orta veya şiddetli) \\
\hline Topiramat & Ön üveit (hafiften şiddetliye kadar) \\
\hline TNF İnhibitörleri (Etanersept, İnfliksimab, Adalimumab) & Sıklıkla Ön üveit (hafif veya orta) [arka, pan üveit de olabilir] \\
\hline Topikal Ajanlar & Üveit Tipi ve Şiddeti \\
\hline Metipranolol & Ön üveit (hafif veya orta) \\
\hline Glukokortikoidler & Ön üveit (hafif veya orta); steroid çekilmesi ile ilişkili olabilir. \\
\hline Brimonidin & Ön üveit (hafif veya orta); granülomatöz olabilir \\
\hline Prostoglandin Analogları (latanoprost, travoprost, bimatoprost) & Ön üveit (hafif); kistik maküler ödem ile ilişkili olabilir \\
\hline Göz İçi (intraoküler) Ajanlar & Üveit Tipi ve Şiddeti \\
\hline $\begin{array}{r}\text { Anti-VEGF ajanlar (ranibizumab, bevasizumab, } \\
\text { pegaptanib, } \\
\text { afilbersept) }\end{array}$ & Panüveit (hafiften şiddetliye kadar) \\
\hline Sidofovir & Panüveit (hafiften şiddetliye kadar) \\
\hline Triamsinolon asetonid & Panüveit (hafiften şiddetliye kadar) \\
\hline Aşılar & Üveit Tipi ve Şiddeti \\
\hline Bacille Calmette Guerin (BCG) aşısı & Ön-orta-arka-pan üveit (hafiften şiddetliye kadar) \\
\hline Kızamık, Kızamıkçık, Kabakulak & Ön-orta-arka-pan üveit (hafiften şiddetliye kadar) \\
\hline Enflüanza & Ön-orta-arka-pan üveit (hafiften şiddetliye kadar) \\
\hline Hepatit B & Ön-orta-arka-pan üveit (hafiften şiddetliye kadar) \\
\hline
\end{tabular}

Orta üveitlere sebep olabilen non enfeksiyöz inflamatuvar durumlar ön planda MS, Sarkoidoz, inflamatuvar barsak hastalığı, Behçet Hastalığı ve amiloidozu içerir. Çeşitli çalışmalarda MS hastalarında orta üveit görülme oranı \%327 olarak tespit edilmiştir. Öte yandan, izole orta üveitli hastaların da \%7,8-16'sinde MS geliştiği gösterilmiştir(21,22). Sarkoidoz tanılı hastaların ise \%2326 'sında orta üveit görülürken, orta üveitli hastaların \%210'unda Sarkoidoz saptanmaktadır. Her iki durumda da bilateral üveitik tutulum tipiktir ancak, MS'de her iki gözde bulunma oranı \%90'ları bulmaktadır. İnflamatuvar barsak hastalığı, Behçet ve amiloidoz orta üveit hastalarının oldukça az bir kısmını oluşturur (23).

\section{Arka Üveitler:}

Gözün retina ve koroid katmanında olmak üzere arka segmentinde sınırlı kalan üveitlerdir. Ön üveitlerde beklenen kırmızı göz, ağrı gibi semptom ve bulgular arka üveitlerde beklenmez. Vitreus bulanıklığı, görme alanında uçuşan cisimler görme bulanıklığına sebep olurken maküla ödemi ve optik sinir etkilenimi görme kayıplarına yol açabilir. Türkiye'de 2018 tarihli üveit kütüğünde kayıtlı tüm üveitlerin $\% 19,9$ 'unu arka üveitlerin oluşturduğu saptanmıştır (24). Etiyoloji olarak ülkeler arası değişkenlik gösterir. Ülkemizde arka üveit tanılı hastaların \%40'tan fazlasında Behçet Hastalığı bildirilmekteyken, Avrupa verilerinde idiyopatik üveitler, enfeksiyonlar ve Sarkoidoz gibi sebepler ön planda gözlenmektedir $(5,10,25)$. Tüfek saçması (Bird Shot) koryoretinopati ve Serpijinöz Koroidopati de diğer önemli arka üveit nedenlerindendir. SUN çalışma grubu tanımlamasına göre fokal multifokal ve diffüz koroidit, koryoretinit, retinokoroidit, retinit ve nöroretinitler hastalığın klinik paternlerini oluşturmaktadır. Bu paternler hastalığın etiyolojisi için ipucu verebilmektedir. 
Fokal retinitler; toksoplazma, rubella, sistoserkozis ve Üveit Maskeli Sendromlarda görülebilmekte iken multifokal retiniti olan bir olguda immünosüpresif de kullanıyorsa HSV, CMV gibi viral retinitler, sifiliz, mantar enfeksiyonları ve Sarkoidoz tespit edilebilmektedir. Fokal koroidit; toksokara, tüberküloz, nokardiya enfeksiyonlarında, multifokal koroiditler ise histoplazmozis, Vogt-Koyonagi-Harada Hastalığı (VKH) ve Sarkoidozda görülebilmektedir (26). Üveit maskeli sendromlar tüm bu tutulumları yapabilmektedir. Yine bir hastada arka üveit olarak başlayan tutulum orta ve panüveite ilerleyebileceği göz önünde bulundurulmalıdır.
Arka üveitlere retinal vasküler tutulum eşlik edebilmektedir. Retinal vaskülitin eşlik ettiği durumlarda, altta bir inflamatuvar sistemik patolojinin bulunma riski artmıştır. Primer olarak arteritin eşlik ettiği tutulumlarda SLE, PAN, Sifiliz, HSV, VZV, EGPA; primer olarak flebitin eşlik ettiği durumlarda Sarkoidoz, paraviral sendromlar, toksoplazma, HIV ve EALES sendromu, arterit ve flebitin beraber görüldüğü durumlarda ise $\mathrm{MS}$, Behçet ve Wegener Granülomatozu sebep olarak akla gelir (Tablo 3) $(26,27)$.

Tablo 3. Retinal Vaskülit ile Seyreden Durumlar

\begin{tabular}{|ccc|}
\hline Primer Arterit & Primer Flebit & Arterit ve Flebit \\
SLE & Sarkoidoz & Toksoplazmoz \\
Poliarteritis Nodoza & MS & Tekrarlayan Polikondrit \\
Sifiliz & Behçet Hastalığı & Wegener Granülomatozu \\
Herpes Simpleks Virüs Enf. & Tüfek Saçması Retinokoroidopati & Crohn Hastalığı \\
Varisella Zoster Virüs Enf. & HIV Paraviral Sendrom \\
$\begin{array}{c}\text { IRVAN (Idiyopatik retinal vaskülit, } \\
\text { anevrizma \& nöroretinit) } \\
\text { Churg Strauss Sendromu }\end{array}$ & Eales Hastalığı & Donuk Dal Anjiti (Frosted Branch) \\
\hline
\end{tabular}

\section{Panüveitler:}

Ön çember vitrea retina ve/veya koroidin tümünün inflamasyondan etkilenmesi ile pan üveit tablosu oluşmaktadır. Bunlara ek olarak inflamasyona sekonder sklera, lens, optik sinir gibi uvea dışı dokular da etkilenebilir. Genellikle non-enfektif ve granülomatöz inflamasyonla seyreden bir durum olsa da bazı enfeksiyonlar da panüveit tablosuna yol açabilir. Bölgesel farklılıklarla beraber panüveit sebeplerinin non-enfeksiyöz/enfeksiyöz oranı 10/1 şeklinde olup çift taraf/tek taraf; 3/1 orandadır (28). Enfeksiyöz nedenlerden Sifiliz, Tüberküloz, Bruselloz, Lyme, Toksokara, bakteriyel ve mantar enfeksiyonları, inflamatuvar sebeplerden Behçet, Sarkoidoz, HLA-B27 ilişkili üveitler ve nadiren vaskülitler, VKH ile sempatik oftalmi buna sebep olabilir. Tedaviye yanıt vermeyen ileri yaşlı vakalarda lenfoma akılda tutulmalıdır.

Ülkemizde yapılan çalışmalarda panüveit sıklığı \%26,7 ile ön üveitten sonraki ikinci en sık üveit grubunu oluşturur. Behçet Hastalığı ve idiyopatik panüveit önde gelen iki sebebi oluşturmaktadır (10).

\section{ÜVEIT YAPAN ROMATOLOJIK HASTALIKLAR}

\section{Behçet Hastalığı}

Behçet hastalığı, genç erişkinlerde görülen üveitin ülkemizdeki en önemli sebeplerinden biridir. Behçet'e bağlı üveit sıklığı ABD'de üveitin \%0,4'lük bir kısmını oluştururken Japonya'da bu oran \%12-20'lere varmaktadır (29). Ülkemizde ise çoğu çalışmada üveitin en sık sebebi olarak Behçet Hastalığı bulunmaktadır. Hastalık sıklığı cinsiyetler arasında ciddi farklılık göstermese de erkeklerde göz tutulumu, vasküler ve nörolojik tutulumlar daha ağır seyreder. 40 yaşından sonra hastalık başlangıcı sık değildir ve bu olgular geç başlangıçlı Behçet olarak adlandırılmaktadır. Geç başlangıçlı Behçet hastalığında arka üveitten ziyade ön üveit daha sık izlenir. Bu hastalar iyi bir görme prognozu gösterirler (30).

Behçet hastalığında göz tutulumu \%50-70 oranındadır. \%10 kadar olguda başlangıç bulgusu olarak ortaya çıkar. Tutulum; akut başlangıçlı spontan remisyona giren non granülomatöz üveitle karakterizedir. En riskli dönem ilk 2 -3 yıllık dönemdir. Behçet üveiti \%80 ve üzeri oranda her iki gözde birden olur. Başlangıç döneminde unilateral görülebilir (13). Steril hipopiyonun en sık sebeplerinden 
birisi Behçet üveitidir. Bazı kaynaklarda Behçet hastalarında görülen ön üveit sıklığı \%56 gibi yüksek oranlarda bildirilmektedir (31-32). Hastalık kimi zaman kadın hastalarda ön üveit olarak seyredebilir ancak izole ön üveit nadirdir. Behçet hastalığının takiplerinde tipik olarak arka üveit ve panüveit görülür. Farklı serilerde olguların \%3053'ünde arka üveit, \%44-80'inde panüveit geliştiği gösterilmiştir (33). Ülkemizdeki panüveit vakalarının yarıdan fazlasını Behçet hastalığı oluşturmaktadır. Yine arka üveitlerin ülkemizdeki en sık sebebi Behçet hastalığıdır. Bu hastalarda eşlik eden retinal vaskülit sıklıkla gözlenmektedir ve kötü prognozla ilişkilidir.

Behçet üveitinin en sık oküler komplikasyonları; maküler ödem, glokom, katarakt ve optik atrofiyi içerir. Optik sinirin tutulum şekli sıklıkla papillittir. Daha nadir olarak retinal arter ve dal oklüzyonları, iris atrofisi, maküler dejenerasyon, epiretinal membran oluşumu ve retinal neovaskülarizasyon görülür (33-35).

Behçet hastalığını kriterlerinin tam karşılanmadığı üveit ile gelen vakada ayırıı tanı için belirli ipuçları bulunabilir. Tipik vasküler kılıflanma ve hipopiyon varlığında özellikle tabloya skleral ve korneal katılımın olmaması Behçet lehine değerlendirilir. Patlayıcı özellikte başlayıp spontan gerileme ile giden tıkayıcı peri flebit Behçet hastalığını düşündürür niteliktedir. Behçet'te retinal vaskülit ven tutulumu ağırlıklı olmakla beraber arteritik tutulumlar da gösterebilmektedir. Sarkoidozda ise non oklüziv venülit beklenmektedir. Retinal hemorajinin eşlik ettiği superfisial retinal infiltratlar, vitröz bulanıklık ve retinal dal oklüzyonu Behçet hastalığını düşündürür $(34,36)$. HLA-B51 pozitifliği ise toplumda sık görülür ve üveitli olguda tek başına pozitif prediktif değeri 0,3'tür. Bu açıdan sadece üveit ve HLA-B51 pozitifliğini tek başına inkomplet Behçet kabul etmek hatalı tanı konma riskine yol açacaktır (37).

\section{HLA-B27 ilişkili üveit; Ankilozan Spondilit ve Diğer Spondiloartropatiler}

Akut ön üveit HLA-B27 ile ilişkili en sık oküler durum olup bu geni taşıyanların \%1 kadarında görülür. AAU'lu olgularda ise HLA-B27 pozitifliği \%50-55 aralığındadır (38). Rekürren AAU'lu olgularda bu oran $\% 70$ 'lere düzeyindedir. Akut HLAB27 üveiti batı ülkelerindeki non enfeksiyöz hipopiyonun en sık kaynağıdır. AAU tespit edilen HLA-B27 pozitif bireylerin yarısı ila üçte ikisi arasında sistemik bir durumla ilişkisi mevcuttur $(13,39)$.

SpA'ya bağlı vakaların $\% 90$ ve üzeri akut ön üveittir ve $\% 85$ olguda tek taraflı tutulum mevcuttur. Üveit sıklığı; HLA-B27 pozitifliği, sakroiliit varlığı ve 10 yıldan uzun hastalık süresiyle artar. Üveitle SpA'nın kas iskelet sistemi aktivitesi arasında ilişki yoktur. SpA'ya bağlı AAU'nun bilateral olma eğilimi kadınlarda daha sıktır. Hastaların yıllık üveit nüks hızı çeşitli çalışmalarda 0,6-3,3 atak/yıl arasında bulunmaktadır $(40,41)$

Ankilozan spondilitli (AS) hastalarda en sık görülen ekstraartiküler tutulum \%25-40 oranılla üveitlerdir. AAU'lu vakaların ise \%18-34 oranında AS bildirilmiştir(13). HLA-B27 pozitif bir rastgele bir kişide AAU ve AS birlikte görülme oranı \%0,4 iken, HLA B27 negatif kişilerde AS ve AAU birlikte görülme sıklığı \%0,02'dir. Vakaların çoğunda izole ön üveit saptanır fakat HLA-B27 pozitif üveit vakalarının \%17 sinde arka segment etkilenimi de görülebilmektedir. Bu etkilenim çoğunlukla vitrit (\%93), papillit $(\% 82,7)$, nadiren de retinal vaskülit $(\% 24)$ ve pars plana eksudaları $(\% 6,8)$ şeklinde olur (42).

Inflamatuvar barsak hastalığı (iBH) olan olgularda \%40 oranında göz komplikasyonu görülür. Bu komplikasyonların yaklaşık yarısını kuru göz-Sikka semptomları oluşturur. iBH'de sık görülen inflamatuvar oküler durumlar episklerit ve sklerittir. Episklerit, kuru göz dışı en sık oküler komplikasyondur. Bununla beraber episklerit çoğunlukla kendini sınırlandırır. Hasta hekime başvurmadan hastalığı geçiştirebilir. Bu nedenle de çoğu seride üveit en sık komplikasyon olarak belirtilmiştir $(43,44)$. IBH'de üveit sıklığı \% 2-12 aralığında görülür. Bu oran pediatrik olgularda daha düşük seviyededir. Yine pediatrik olgularda semptomsuz üveit saptanabilir. Çoğu pediatrik olgu kendini sınırladığı için JiA'daki gibi rutin bir tarama önerilmez. Büyük bir seride Crohn hastalarında ülseratif kolite nazaran 1,6 kat daha fazla üveit geliştiği gösterilmiştir. Crohn hastalarında kolon ve iliyo-kolonik tutulum varlığı, oküler tutulum riskini 8 kata kadar arttırır. IBH'li kadınlarda üveit görülme insidansı erkeklerden daha fazladır. IBH'da sakroiliyak eklem tutulumu, artrit, HLA-B27 ve ANCA pozitifliği ile üveit arasında ilişki mevcuttur. Ülseratif kolitte HLA-DRB1*0103 alleli, üveitli vakalarda daha sıktır. Bağırsak tutulumuyla üveit aktivitesi arasında ilişki yoktur. Ayrıca üveit, bağırsak tutulumundan yıllar önce gözlenebilmektedir (45). 
IBH'de en sık görülen üveit tipi akut rekürren ön üveittir. Sıklıkla bilateral tutulum yapmaktadır ve $\mathrm{IBH}$ ilişikli üveitlerin $\% 60^{\prime} ı$ ık kısmını oluşturur. Tipik olarak nongranülomatöz düşük dereceli bir inflamasyon gözlenir. Ancak hipopiyon ile veya granülomatöz inflamasyonla seyreden olgular da görülebilir $(46,47)$. IBH ilişikli üveitlerin yalnızca \%10'u monofazik non rekürren ön üveit oluşturur. AS ile kıyaslandığında iBH'ye bağı üveitlerde; sinsi başlangıç, bilateral tutulum, kronikleşme ve arka tutulum oranı daha fazladır. İB üveiti \%10-30 oranında arka üveit veya panüveit şeklindedir ve retinal vaskülit de eşlik edebilir. Nadiren orta üveit tespit edilebilir $(45,47)$.
Akut ön üveitli rastgele bir hastanın Psöriatik Artrit olma olasılığı \%1 civarındadır. Bununla beraber PsA'lı hastalarda üveit sıklığı \%7-10'lara çıkabilmektedir $(13,48)$. PsA'da tipik olarak üveitten önce eklem bulguları belirir. PsA'da üveit sinsi başlangıçlı ve bilateral olmaya meyillidir. Aynı zamanda PsA'lı hastalar diğer SpA'lara nazaran arka üveit gelişimine daha meyillidir (Tablo 4). Üveitli hastaların \%43'ünde sakroiliit, \%28'inde spondilit saptanmıştır. PsA'da aksiyel tutulum, sakroiliit ve daktilitin üveitle ilişkili olabileceğini gösteren çalışmalar vardır. Aksiyel tutulumlu PsA'ılarda üveit AS'dekine benzer olarak akut ön üveit şeklinde klinik vermeye meyillidir (49).

Tablo 4. SpA'da görülen Üveit Tipleri

\begin{tabular}{|ccccc|}
\hline & PsA & AS & ReA & IBH \\
Prevalans (\%) & $1-25$ & $20-40$ & $12-26$ & $2-12$ \\
Başlangıç & Akut/Sinsi & Akut & Akut & Sinsi \\
Lokalizasyon & Ön/Arka & Ön & Ön & Ön/Arka \\
Taraf & Bilateral & Unilateral & Unilateral & Bilateral \\
HLA-B27 & $+/-$ & + & + & $+/-$ \\
Eklem & Önce & Önce & Sonra tutabilir & Sonra tutabilir \\
Erkek/Kadın & Değişken & $2 / 1$ & $2 / 1$ & Değişken \\
\hline
\end{tabular}

Jüvenil PsA'ı çocuklar da Ji'A'ılar gibi ciddi üveit riskiyle karşı karşıyadır. Kronik üveit tanılı çocuk hastalarda \%13'e kadar jüvenil PsA olabileceği gösterilmiştir. Oligoartiküler jüvenil psöriatik artritin üveit oranı JiA'lılarla benzerken poliartiküler formda PsA'ı çocuklarda Ji'A'dan daha sık üveit saptanmıştır. Jüvenil PsA'ılıardaki üveit erişkin PsA'dan ziyade JiA üveitine benzer kronik ön tutulum göstermekte olup bu sebeple tarama programı gereklidir(50).

Reaktif Artrit (ReA) oküler tutulumunda, \%30 oranında konjonktivit, \%5-12 oranında üveit gözlenebilir. Üveit vakaları akut tek taraflı ön üveit olarak seyreder. Fakat rekürren ataklar sırasında diğer göz de etkilenebilir. Üveit HLA-B27 (+) ve sakroiliyak tutulumu olan ReA'da daha sık izlenir (13).

\section{Jüvenil Idiyopatik Artrit}

Üveit, JíA hastalarında çeşitli çalışmalarda \%12-20 oranında tanımlanmıştır. Uzamış oligoartiküler tip JiA'da üveit görülme oranı \%12-25 kadardır. Persistan poliartiküler tipte bu oran \%16 civarındadır (51). Klasik JíA üveiti sinsi başlangıçlıdır, non-granülomatözdür ve ön üveittir. Genelde kırmızı göz yoktur ve asemptomatiktir. O kadar ki kimi hastalar okul taramaları sırasında görme kaybı nedeniyle oftalmoloğa yönlendirilip tanı almaktadırlar. Bu semptomsuz durum beyaz göz üveiti olarak adlandırıır (13).
JiA'ya üveitin eklendiği olguların yarıdan fazlasında ANA pozitifliği gözlenir (52). Göz bulguları \%80-90 oranda artriti takip eden ilk 4 yıl içinde gelişir. Hastaların çoğunda kronik ön üveit görülürken azalan sıklıkla akut anterior, rekürren akut ön ve panüveitik tutulumlar da bildirilmiştir (53). Tutulum 2/3 oranda bilateral olup unilateral başlangıçların önemli bir kısmı da 1 yıllık süreçte çift tarafılık göstermektedir. Hastalarda vitrit kistik maküler ödem ve optik disk ödemi gibi arka segment bulguları görülebilir. Entezit ilişkili forma bağlı üveit erişkin spondiloartrit ilişkili üveitlerle benzer şekilde daha komplikasyonsuz olan akut ön üveit olarak görülme eğilimindedir.

JiA'da ANA pozitifliği ve oligoartiküler tutulum üveit için majör risk faktörleridir. Bu hastalarda üveit oranı \%30'ları bulur. ANA (+) poliartiküler grupta da oligoartiküler form ile benzer risk oranı varlığını iddia eden çalışmalar vardır ve ANA (+)'nin eklem paterninden daha anahtar bir rol oynadığı izlenmektedir (13). Romatoid Faktör (RF) pozitifliği düşük üveit riski ile ilişkilidir. Kız çocuklarının üveitten daha sık etkilendiği varsayılır. JiA üveitine bağlı körlük geçmişte $\% 40$ larda iken, günümüzde \%3-10'lara gerilemiştir. Buna rağmen JiંA'ı çocukların \%25'i görme açısından bir miktar etkilenir. Hastaların üveit atakları \%30-50 oranda erişkinlikte de devam eder (54). 
JIA'lı çocuklar şikâyetleri olmasa da üveite karşı oftalmolojik kontrolleri sıkı tutulmalıdır. Önerilen sıklık üveit riskini belirgin olduğu ANA (+), 6 yaş ve öncesi başlamış, 4 yıldan kısa süreli, oligoartiküler-poliartiküler formlarda; 3 ayda bir iken, sistemik JiA'da risk az olduğundan yılda bir kontrol yeterlidir (Tablo 5 ) (55).

Tablo 5. Jüvenil idiyopatik artritli çocuklarda oftalmolojik muayene sıklı̆̆ı

\begin{tabular}{|c|c|c|c|c|c|}
\hline Risk düzeyi & Artrit tipi & Başlangıç yaşı & ANA & Hastalık süresi & Tarama sıklığı \\
\hline Yüksek & Oligo/poliartiküler & $<6$ & + & $\leq 4$ & 3 ay \\
\hline Orta & Oligo/poliartiküler & $\leq 6$ & + & $>4$ & 6 ay \\
\hline Orta & Oligo/poliartiküler & $>6$ & + & $\leq 4$ & 6 ay \\
\hline Orta & Oligo/poliartiküler & $\leq 6$ & - & $\leq 4$ & 6 ay \\
\hline Düşük & Oligo/poliartiküler & $\leq 6$ & + & $>7$ & 12 ay \\
\hline Düşük & Oligo/poliartiküler & $>6$ & + & $>4$ & 12 ay \\
\hline Düşük & Oligo/poliartiküler & $<6$ & - & $>4$ & 12 ay \\
\hline Düşük & Oligo/poliartiküler & $>6$ & - & Bilinmiyor & 12 ay \\
\hline Düşük & Sistemik & Bilinmiyor & Bilinmiyor & Bilinmiyor & 12 ay \\
\hline
\end{tabular}

\section{Sarkoidoz}

Sarkoidozun en sık oküler tutulumu üveittir. Referans merkezlerdeki üveitlerin farklı serilere göre \%3-10 kadarını Sarkoidoz oluşturur (56-58). Sarkoidoz vakalarının ise \%25'inde üveit gözlenir. Siyah ırkta göz tutulumu daha sıktır ve ön üveit belirgindir. Arka üveit ise yaşlı kadın ve beyaz ırkta daha sık görülür. Yine Japonlarda Sarkoidoz'un daha fazla oküler tutulum yaptığı bildirilmiştir. Sarkoidoz vakalarının \%20'sinde doktora ilk başvuru üveit nedeniyledir ve sonrasında tanı konulur. Sarkoidoz üveiti $\% 85$ granülomatöz formdadır; hastalarda mutton fat keratik presipitatlar, iris nodülleri, nodüler segmental periflebit, retina, optik sinir ve koroitte aktif granülomlar saptanır. Bilateral tutulum $\% 80$ ve üzeridir fakat inflamasyon asimetrik de olabilir. Göz kapakları ve konjonktiva tutulumunda biyopsi \%36-75'lik bir tanı gücü sağlayabilir(59-61). Konjonktiva nodülleri tipik sarımsı-altın renkli, pigmentsiz tombul nodüller olarak üst palpebral konjonktivada daha sık görülür. Ön üveit olguların \%66$85^{\prime}$ inde görülerek en sık tutulum şeklini teşkil eder. Kimi olgular tanı konulduğu atakla sınırlı olsa da kronik ön üveit gelişebilir. Sarkoidoz orta üveitin de önemli bir sebebidir. Arka tutulumda vitrit ve vaskülit sık olarak gözlenir. Retinal venüller segmental periflebit olarak tutulur, oldukça nadir olarak arteriolit yapabilir (60).

\section{Vaskülitler ve Diğer Nadir Sebepler}

Üveit ANCA ilişkili vaskülitlerden en sık GPA ile ilişkilendirilmiştir. GPA'ı hastaların \%8-16'ık kısmında oftalmolojik tutulum saptanır. Episklerit, sklerit ve konjonktivit en sık oküler tutulumlar olarak göze çarpar. Uveal etkilenim ve granülomatöz sklero-üveit çok daha nadir bir durumdur (62). Oküler tutulumu olan GPA'ılırın \%10 veya daha azında üveit vardır (63). GPA'da görülen üveit unilateral veya bilateral olabilir. Ön arka ve pan üveit durumlarının hepsi daha önce GPA'da tanımlanmıştır. Bu durumlar sıklıkla eş zamanlı sklerit ile beraber görülür. GPA hastalarındaki üveitin \%70'i ön üveittir. Görülen üveit akut, granülomatöz veya kronik seyir gösterebilir. Arka üveit ise oldukça nadirdir ve vakaların ancak \% 5'ini temsil eder (64). Yine burada da eş zamanlı arka sklerit gözlenebilmektedir. Arka tutuluma ciddi vazooklüzif hastalık, retinal vaskülit, trombozlar, optik nöropati eşlik edebilir. GPA vakalarında sklerit kimi zaman hastalığın başlangıç bulgusu veya tanı anındaki bulgu olarak görülebilirken, üveit vakaları genelde oturmuş kliniği olan hastalarda gözlenir. Mayo klinikte takipli 1171 ANCA ilişkili vaskülitin geriye dönük incelenmesinde 16 olguda üveit saptanmış; bunun 15'i GPA olarak bulunmuştur. Bu hastalardan 14'ünde PR3-ANCA, 1'inde MPO-ANCA (+) olup, 1 'inde ise ANCA negatiftir(65,66).

Sistemik Lupus Eritematozus (SLE), Sjögren Sendromu (SjS) ve diğer romatolojik hastalıklarla ile ilişkili olarak üveit çok çok nadir de olsa tanımlanmıştır ve bu hastalarda üveiti hastalığa bağlamadan önce muhakkak ilaç ve benzeri diğer durumlar gözden geçirilmelidir. Hipokomplementemik ürtikeryal vaskülit bu durumlardan biri olup neredeyse birebir olarak SLE'yi taklit edebilen tutulumlar yapabilir. Klinik olarak SLE ile farklıııklarından biri üveit yapabilmesi ve 
KOAH sıklığının artmış olmasıdır. Kriyoglobulinemik vaskülit de SjS birlikteliği olan, ilaveten nadir de olsa üveite sebep olabilecek bir durumdur. Hem HUVS hem de Kriyoglobulinemik Vaskülit genellikle kronik ön uveal tutulum yaparlar (13).

Çoğunlukla çocuk romatoloji hekimlerinin karşılaştığı Kawasaki Hastalığı ve BLAU sendromu da nadir üveit yapabilen hastalıklardandır. Kawasaki'de ılımlı bir ön üveit beklenirken BLAU sendromunda bilateral kronik ön üveit tutulumu veya panüveit tutulumu görülür. Bu sebeple bu hastalar yanlışlıkla JIA veya Sarkoidoz tanıları alabilirler (1367).

Yazarlar arasında çıkar çatışması yoktur.

The author declares no conflict of interest.

Finansal Destek: yoktur / Funding : none

doi: https://doi.org/10.33713/egetbd.644034

\section{KAYNAKLAR}

1. Şengün A. Sınıflandırma. In:Akbatur H(ed). Behçet Hastalığı Endoftalmiler ve Üveitler. Ankara: AtlasYayıncılık;2002:27-32

2. Thorne JE, Suhler $E$, Skup $M$, et al. Prevalence of Noninfectious Uveitis in the United States: A Claims-Based Analysis. JAMA Ophthalmol. 2016;134(11):1237-1245

3. Rosenbaum, J. T. Uveitis: etiology, clinical manifestations, and diagnosis. UpToDate [Cited 24.10.2019] Avaible from: https://www.uptodate.com/contents/uveitis-etiology-clinicalmanifestations-and-diagnosis

4. Pivetti-Pezzi $P$, Accorinti $M, L a$ Cava $M$ et al: Endogeneous uveitis: an analysis of 1417 cases. Ophthalmologica 1996;210:234-8

5. Özdal M , Yazıcı A , Tüfek M et al . Epidemiology of uveitis in a referral hospital in Turkey. Turkish Journal of Medical Sciences. 2014; 44(2): 337-342

6. Rodriguez A, Calonge $M$, Pedroza-Seres $M$ et al. Referral patterns of uveitis in a tertiary eye care center. Arch Ophthalmol 1996;114(5):593-9

7. Hosseini SM , Shoeibi N , Ebrahimi R et al.Patterns of Uveitis at a Tertiary Referral Center in Northeastern Iran. J Ophthalmic Vis Res 2018; 13 (2): 138-143

8. Rathinam SR, Babu M. Algorithmic approach in the diagnosis of uveitis. Indian J Ophthalmol. 2013;61(6):255-262

9. Jabs DA, Nussenblatt RB, Rosenbaum JT et al. Standardization of uveitis nomenclature for repoating clinical data. Results of the first international workshop. Am J Ophthalmol 2005;140(3):509-16

10. Haluk Kazokoglu, Sumru Onal, Ilknur Tugal-Tutkun et al. Demographic and

Clinical Features of Uveitis in Tertiary Centers in Turkey,
Ophthalmic Epidemiology, 2008;15(5): 285-293

11. Chan S, Gan K, Weis E. (2010). Characteristics and predictors of recurrence of anterior and intermediate uveitis in a Canadian referral centre. Can J Ophthalmol.2010;45: 144-8.

12. Otasevic L, Zlatanovic G, Stanojevic-Paovic A et al. Helicobacter pylori: An Underestimated Factor in Acute Anterior Uveitis and Spondyloarthropathies? Ophthalmologica 2007;221:6-13.

13. Khan IR, Thorne JE, Jabs DA. The eyes in rheumatic disease. In Hochberg M (ed) Rheumatology 7th ed, Philadelphia, Elsevier 2019:279-85.

14. Zaidi AA, Ying GS, Daniel $E$, et al. Hypopyon in patients with uveitis. Ophthalmology. 2010;117(2):366-372.

15. Hansen BA, Soukiasian SH. Approach to the Laboratory, Imaging and Molecular work-up for uveitis, In: Papaliodis GN (ed) , Uveitis, Switzerland , Springer 2017 : 9-34

16. Bhagat N, Read RW, Rao NA et al. Rifabutin-associated hypopyon uveitis in human immunodeficiency virus-negative immuncompetent individuals. Ophthalmol. 2001;108(4):750-2

17. McCluskey PJ, Towler HM, Lightman S. Management of chronic uveitis. BMJ. 2000;26;320(7234):555-8

18. Akbatur H. Orta Üveitler . In:Akbatur H(ed). Behçet Hastalığ Endoftalmiler ve Üveitler. Ankara: AtlasYayıncılık;2002:131-38

19. Janigian RH. Intermediate Uveitis: Medscape [Cited 24.10.2019] Avaible from: https://emedicine.medscape.com/article/1208794-overview

20. Grillo A, Levinson RD, Gordon LK. Practical diagnostic approach to uveitis. Expert Review of Ophthalmology, 2011; 6(4), 449-459.

21. Kaya D, Kaya M, Özakbaş S, İdiman E. Uveitis associated with multiple sclerosis: complications and visual prognosis. Int J Ophthalmol. 2014;7(6):1010-1013.

22. Burkholder BM, and James PD. "Multiple sclerosisassociated uveitis." Expert Review of Ophthalmology, 2012: 7(6): 587.

23. Babu BM, Rathinam SR. Intermediate uveitis. Indian Ophthalmol. 2010;58(1):21-27.

24. Yalçındağ FN, Özdal PC, Özyazgan $Y$ et al. Demographic and Clinical Characteristics of Uveitis in Turkey: The First National Registry Report. Ocular Immunology and Inflammation, 2018;26(1): 17-26

25. Hautala, N, Siiskonen, M. , Salmi, J. and Hautala, T., Aetiology of posterior uveitis in a tertiary centre in Finland. Acta Ophthalmol. 2019 doi:10.1111/aos.14182

26. Akbatur H. Arka Üveitler . In:Akbatur H(ed). Behçet Hastalığı Endoftalmiler ve Üveitler. Ankara: AtlasYayıncılık;2002:151-58

27. Abu El-Asrar Ahmed M, Herbort CP, Tabbara KF. Differential diagnosis of retinal vasculitidis. Middle East Afr J Ophthalmol. 2009 ; 16(4): 202-18

28. Akbatur H. Arka Üveitler . In:Akbatur H(ed). Behçet Hastalığı Endoftalmiler ve Üveitler. Ankara: AtlasYayıncılık;2002:335-43 
29. Bashaour M. Ophthalmologic manifestations of Behcet Disase Medscape [Cited 24.10.2019] Avaible from: https://emedicine.medscape.com/article/1229174-overview\#a6

30. Hazirolan D, Sungur G, Duman S. Demographic,clinical and ocular features in patients with late-onset Behcet Disase. Ocular Immunol Inflamm. 2012; 20(2): 119-24

31. Kaçmaz RO, Kempen JH, Newcomb J et al. Systemic Immunssupressive Therapy for Eye Disases Cohort Study Group. Ocular Inflammation in Behçet Disase: incidence of ocular complications and loss of visual acuity. Am J Ophthalmol . 2008;146:828-836.

32. Thorne JE, Jab DA. Rheumatic disases. In: Ryan SJ, ed. The retina 6th ed. London: Elsevier;2012:1383-1408

33. Khairallah M, Accorinti M, Muccioli $C$ et al. Epidemiology of Behcet disase. Ocular Immunol Inflamm. 2012;20(5):324-35

34. Lorch A, Sobrin L. Adamantiades-Behçet's Disase. In: Papaliodis GN (ed) , Uveitis, Switzerland, Springer 2017 : 121-27

35. Sahli E, Koz ÖG. Ocular Manifestations of Behçet's Disase. IntechOpen [Cited 24.10.2019] Available from: https://www.intechopen.com/books/behcet-s-disease/ocularmanifestations-of-beh-et-s-disease

36. Tugal IT, Onal S, Ozyazgan Y et al. Validity and Agreement of Uveitis Experts in Interpretation of Ocular Photographs for Diagnosis of Behçet Uveitis, Ocular Immunology and Inflammation 2014; 22(6. : 461-8

37. Zamecki KJ, Jabs AD. HLA typing in uveitis: use and misuse. Am J Ophthalmol. $2010 ; 149(2): 189-193$.

38. Brewerton DA, Caffrey M, Nicholls A, et al. Acute Anterior Uveitisi and HLA-B27 Lancet. 1973:994-6

39. Letko E.HLA-B27. In: Papaliodis GN (ed), Uveitis, Switzerland , Springer $2017: 171-76$

40. Sharma SM, Jackson D, Uveitis in the Spondyloarthopathies Best Practice \& Research Clinical Rheumatology (2017);31: 846862

41. de la Maza DS. Seronegative Spondyloarthropaties In :Foster CS (ed) Diagnosis and treatment of Uveitis, Philadelphia WB Saunders Company :581-601.

42. Dacey M. Ankylosing Spondylitis. In: Papaliodis GN (ed) , Uveitis, Switzerland, Springer 2017 : 135-41.

43. Ghanchi FD,Rembacken BJ. Inflammatory bowel disase and the eye. Surv Ophthalmol. 2003;48(6): 663-76

44. Felekis $T$, Katsonos $K$, Kitsanou $M$ et al. Spectrum and frequency of ophthalmologic manifestations in patients with inflammatory bowel disase: a prospective single center study. Inflamm Bowel Dis. 2009;15(1): 29-34

45. DS, Butler NJ. Inflammatory bowel disase. In: Papaliodis GN (ed) , Uveitis, Switzerland, Springer 2017 : 177-82.

46. SalmonJF, Wright Jp, Murray AD . Ocular inflammation in Chron 's Disase . Opthalmology. 1991; 98 (4): 480-4

47. Lyons JL, Rosenbaum JT. .Uveitis associated with inflammatory bowel disase compared with uveitis associated with spondyloarthropathy. Arch Ophthalmol 1997;115(1):61-4
48. Kammer GM, Soter NA, Gibson DJ et al Psoriatic arthritis: a clinical, immunologic and HLA Study of 100 patients. Semin Arthritis Rheum. 1979;9(2):75-97

49. Hunter R. Psoriasis Associated. In: Papaliodis GN (ed) , Uveitis, Switzerland, Springer 2017: 221-29

50. Butbul YA, Tyrrell PN, Schneider $R$ et al. Comparision of patients with juvenile psoriatic arthritis and nonpsoriatic juvenile idiopathic arthritis: how different are they? J Rheumatol. 2009; 36(9):2033-41.

51. Heiligenhaus $A$, et al.Prevelance and complications of uveitis in juvenile idiopathic arthritis in a population-based nationwide study in Germany: suggested modification of current screening guidelines. Rheumatology (oxford) 2007;46 (6):1015-9

52. Angeles-Han ST, McCracken C, Yeh S, et al. Characteristics of a cohort of children with Juvenile Idiopathic Arthritis and JIAassociated Uveitis. Pediatr Rheumatol Online J. 2015;13:19.

53. Sen ES, Ramanan AV. Juvenile Idiopathic Arthritis associated uveitis Best Practice \& Research Clinical Rheumatology 2017;31: 517-534

54. Lobo AM. Juvenile İdiopathic Arthritis. In: Papaliodis GN (ed) , Uveitis, Switzerland, Springer 2017 :183-8

55. Angeles-Han ST, Ringold S, Beukelman T et al. 2019 American College of Rheumatology/Arthritis Foundation Guideline for the Screening, Monitoring, and Treatment of Juvenile Idiopathic Arthritis-Associated Uveitis . Arthritis Care Res (Hoboken). 2019 Jun;71(6):703-716

56. Blaise $P$, Ferdeau $C$, Chapelon $C$ et al. Minor salivary gland biopsy in diagnosing ocular sarcoidosis. $\mathrm{Br} J$ Ophthalmol. 2011;95(12):1731-4

57. Rithıva A, Alberts C, Glasius E et al. Risk factors for ocular sarcoidosis. Doc Ophthalmol. 1989;72(3-4):287-96

58. Jones NP. The Manchester uveitis clinic: the first 3000 patients-epidemiology and casemix. Ocul Immunol Inflamm. 2015;23(2):118-26

59. Pepple KL, Van Gelder RN. Sarcoidosis. In: Papaliodis GN (ed) , Uveitis, Switzerland, Springer 2017 :243-52

60. Akbatur H. Sarkoidozis. In:Akbatur H(ed). Behçet Hastalığ Endoftalmiler ve Üveitler. Ankara: AtlasYayıncılık;2002:177-90

61. Dana MR, Merayo-Lioves J, Schaumberg DA et al. Prognosticators for visual outcome in sarcoid uveitis. Ophthalmology 1996;103:1846-53

62. Rahmani S. Uveitis in GPA: In: Papaliodis GN (ed), Uveitis, Switzerland, Springer $2017: 291-93$

63. Rothschild PR, Pagnoux C, Seror R et al. Ophthalmologic manifestations of systemic necrotizing vasculitides at diagnosis: a retrospective study of 1286 patients and review of the literatura. Semin Arthritis Rheum. 2013;42(5):507-14

64. Watkins As, Kempen JH, Choi D et al. Ocular disase in patients with ANCA-positive vasculitidis. J Ocul Biol Dis Infor. 2012;3(1):12-9

65. Kubaisi B, Abu Samra K, Foster CS. Granulomatosis with polyangiitis (Wegener's): An updated review of ocular disease 
manifestations. Intractable Rare Dis Res. 2016;5(2):61-69.

66. Ungprasert $P$, Crowson CS, Cartin-Ceba R, et al. Clinical characteristics of inflammatory ocular disease in anti-neutrophil cytoplasmic antibody associated vasculitis: a retrospective cohort study. Rheumatology (Oxford). 2017;56(10):1763-1770

67. Soukiasian SH .Wegener's Granulomatosis In :Foster CS (ed) Diagnosis and treatment of Uveitis, Philadelphia WB Saunders Company :661-675. 